\title{
АНАЛИЗ ДВИЖЕНИЙ В КОЛЕННОМ СУСТАВЕ В ШАГОВОМ ЦИКЛЕ У ЮНОШЕЙ И МУЖЧИН 17-25 ЛЕТ
}

\author{
(C) Удочкина Л.А. ${ }^{1}$, Воронцова О.И. ${ }^{4}$, Галушко Т.Г. ${ }^{1}$, Гончарова Л.А. ${ }^{2}$, Ахминеева А.Х. ${ }^{3}$, Мазин И.Г. ${ }^{4}$ \\ ${ }^{1}$ Кафедра анатомии, ${ }^{2}$ кафедра детской хирургии, ${ }^{3}$ кафедра профилактической медицины и здорового \\ образа жизни Астраханского государственного медицинского университета, Астрахань; \\ ${ }^{4}$ лаборатория изучения биомеханики движений человека \\ Астраханского государственного университета, Астрахань \\ E-mail: irina-nurzhanova@yandex.ru
}

\begin{abstract}
На основании данных, полученных при помощи системы захвата и анализа движения, определены кинематические параметры коленного сустава в шаговом цикле у 25 мужчин 17-25 лет нормостенического телосложения. Амплитуда движений в коленном суставе составила: сгибание $-53,8 \pm 1,2^{\circ}$, осевая ротация голени $-9,4 \pm 0,4^{\circ}$, боковое смещение коленного сустава $-12,9 \pm 0,5^{\circ}$. На основании корреляционного анализа выявлена сильная связь между сгибанием в коленном суставе и изменением установки колена (варус/вальгус), а также связь средней силы между установкой колена и осевой ротацией голени. Коэффициент ассоциации слабой силы является показателем стабильности коленного сустава при его разгибании, а средней силы - меньшей стабильности при его сгибании.
\end{abstract}

Ключевые слова: коленный сустав, шаговый цикл, мужчины, кинематические параметры.

\section{ANALYSIS OF KNEE JOINT MOTIONS IN STEP CYCLE IN YOUNG AND ADULT MEN OF 17-25 YEARS}

Udochkina L.A. ${ }^{1}$, Vorontsova O.I. ${ }^{4}$, Galushko T.G. ${ }^{1}$, Goncharova L.A. ${ }^{2}$, Akhmineeva A.Kh. ${ }^{3}$, Mazin I.G. ${ }^{4}$

${ }^{1}$ Department of Anatomy, ${ }^{2}$ Department of Children Surgery, ${ }^{3}$ Department of Preventive Medicine and Healthy Lifestyle of Astrakhan State Medical University, Astrakhan;

${ }^{4}$ Laboratory of Investigation of Human Movements Biomechanics of Astrakhan State University, Astrakhan

The data received with the help of capture system and movement analysis helped to determine the cinematic parameters of knee joint in step cycle of 25 men aged 17-25 with normosthenic body type. The amplitude of motions in a knee joint was: in flexion- $53.8 \pm 1.2^{\circ}$; knee axis rotation $-9.4 \pm 0.4^{\circ}$; lateral knee displacement $-12.9 \pm 0.5^{\circ}$. The correlation analysis revealed the strong link between knee joint flexion and lateral knee displacement and its axis rotation. The factor of weak power association may indicate the knee joint stability in extension and mild power indicates the less stability in its flexion.

Keywords: knee joint, step cycle, men, cinematic parameters.

Ходьба относятся к циклическим локомоциям, включающим широкий спектр движений. Шаговый цикл (ШЦ) представляет собой минимальный модуль ходьбы, ограниченный периодом времени от начала контакта стопы с опорой до начала следующего контакта этой же стопы с опорой. Его принято разделять на цикл правой ноги и цикл левой ноги, в каждом из которых выделяют период двойной опоры и период одиночной опоры [10].

В биомеханическом отношении коленный сустав является одним из самых напряженных и сложных. Он выполняет не только опорную и локомоторную функции, но и обеспечивает равновесие в переднезаднем направлении во время движения, а также несет на себе значительную нагрузку, связанную с перемещением тела в пространстве [2, 12].

Современные методы исследования, в частности системы видеоанализа, дают возможность создавать трехмерные модели, позволяющие получать объективную информацию о движениях сегментов локомоторного аппарата человека $[3,16,17,18]$.

Цель исследования - определить кинематику коленного сустава в каждой фазе шагового цикла.

\section{МАТЕРИАЛЫ И МЕТОДЫ ИССЛЕДОВАНИЯ}

Материалом для анализа послужили результаты исследования 25 добровольцев юношей и мужчин первого периода зрелого возраста, проведенного в лаборатории по изучению биомеханики движений человека Астраханского государственного университета. Средний возраст обследованных составил $19,08 \pm 0,9$ года.

Условием включения в группу являлось заключение терапевта и ортопеда об отсутствии у обследованных хронических заболеваний, патологии опорно-двигательного аппарата и травм коленного сустава, нормостенический тип телосложения. 


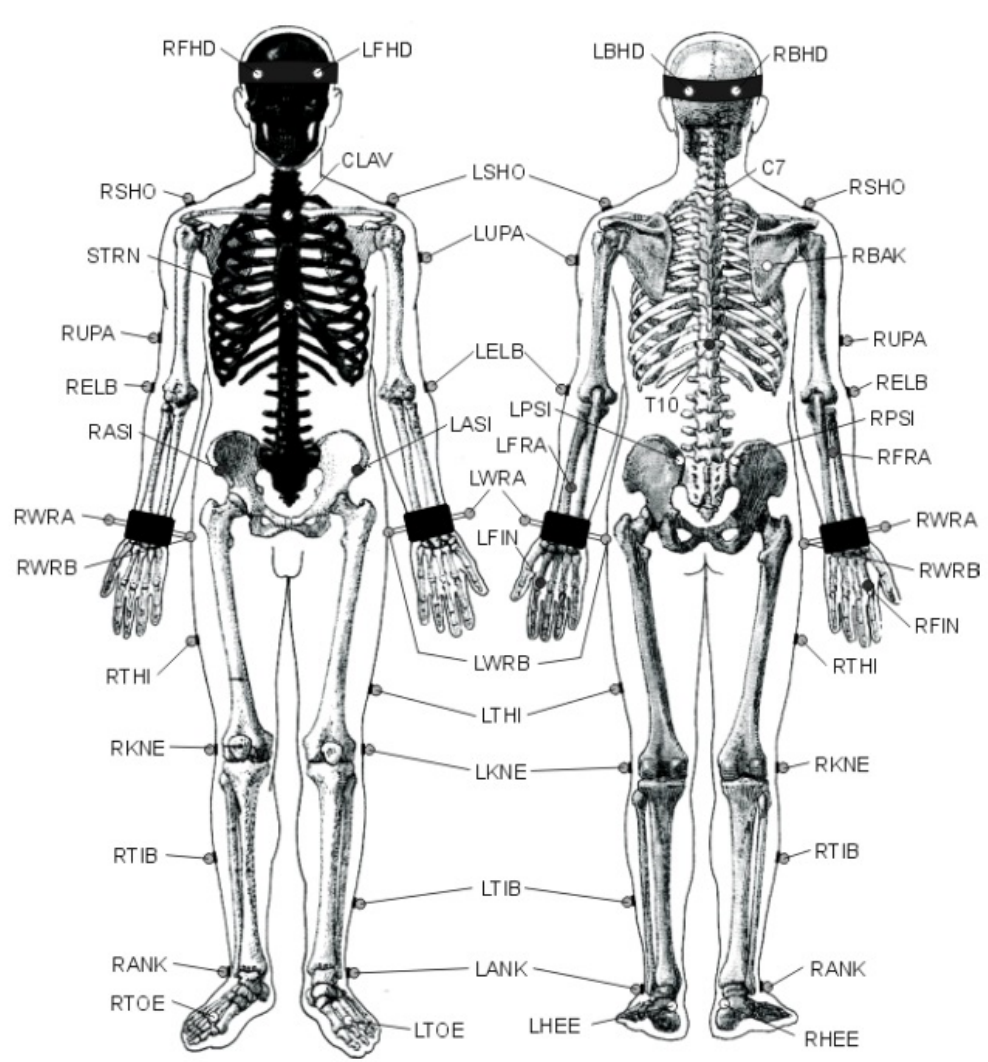

Рис. 1. Схема установки светоотражающих датчиков Plug in Gait Full body [14].

С целью формирования однородной группы проведено антропометрическое обследование 245 юношей и мужчин первого периода зрелого возраста $[1,4,6,8]$. Соматотипирование осуществлялось с использованием индекса Пинье [11] по формуле:

\section{Индекс Пинье $=$}

$$
\text { рост - (вес + окружность грудной клетки) }
$$

На основании Индекса Пинье проводили соматотипирование в соответствии с классификацией М.B. Черноруцкого [15]: величина индекса Пинье более 30 соответствовала астеническому телосложению, от 10 до 30 - нормостеническому, менее 10 гиперстеническому.

Антропометрические характеристики юношей и мужчин первого периода зрелого возраста, включенных в группу исследования, были следующими: средний рост $176 \pm 5,4$ см, вес $75,5 \pm 3,2$ кг, окружность грудной клетки $84,8 \pm 1,3$ см. Индекс Пинье составил $16,75 \pm 0,48$, что соответствует нормостеническому типу телосложения.

Исследование шагового цикла осуществлялось при помощи системы захвата и анализа движения фирмы "Vicon" ("Vicon", Oxford, Great Britain), включающей 10 инфракрасных камер "Vicon T40" (240 Гц), двухсекционную динамометрическую платформу AMTI (model (OR6-5-1000, Watertown MA, USA) и программное обеспечение "Vicon Nexus" и
"Vicon Polygon". В работе использована модель Plug-in-Gait Full body c 32 маркерами, устанавливаемыми на испытуемом в соответствии с Руководством по использованию программного модуля «Plug-In-Gait» [14] по схеме, приведенной на рисунке 1.

Для получения качественной индивидуальной скелетной модели по методике В.В. Бунака [4] определялись антропометрические данные каждого обследуемого (рост, длина нижней конечности, длина бедра, длина голени, обхваты нижней конечности на уровне коленного и голеностопного суставов, обхваты верхней конечности на уровне локтевого и лучезапястного суставов, а также толщина ладони) и вносились в специальное поле программного обеспечения.

Расчет угла сгибания/разгибания в коленном суставе определялся программой как угол между проекцией сагиттальной оси голени и сагиттальной оси бедра на плоскость, перпендикулярную к оси сгибания в коленном суставе. В соответствии с Руководством по использованию программного модуля «Plug-InGait» [14] положительный угол соответствует сгибанию нижней конечности в коленном суставе (рис. 2).

Ротация измерялась по продольной оси голени как угол между сагиттальной осью голени и сагиттальной осью бедра, проецирующийся в плоскости, перпендикулярной к продольной оси голени. Полученные результаты оценивали в 
соответствии с Руководством по использованию программного модуля «Plug-In-Gait» [14]: положительный угол соответствовал внутреннему вращению голени (рис. 2).

Варусную или вальгусную установки коленного сустава определяли в плоскости сгибания коленного сустава и центра голеностопного сустава (плоскости, образованной осью сгибания коленного сустава и центром голеностопного сустава) как угол между продольной осью голени и продольной осью бедра, проектируемого в эту плоскость. Положительное число этого угла соответствовало варусной установке коленного сустава.

Информация, поступающая динамометрических платформ, использовалась для получения кинетических параметров движения испытуемого. Осуществлялось пять последовательных проходов по динамометрической платформе. Работа проводилась при средней температуре воздуха в лаборатории $+23,2 \pm 1,7^{\circ} \mathrm{C}$.

При анализе длительность шагового цикла была принята за 100\%. Кинематические параметры рассматривали с интервалом в 10\% времени от начала шагового цикла.

Bce полученные данные подвергались статистической обработке методами вариационной и непараметрической статистики. Степень точности исследования определена вероятностью безошибочного прогноза меньшим или равным $0,95 \%$; уровнем значимости $\mathrm{P} \leq 0,05$; для признаков с нормальным распределением использован критерий Стьюдента $\mathrm{t}=2$, для

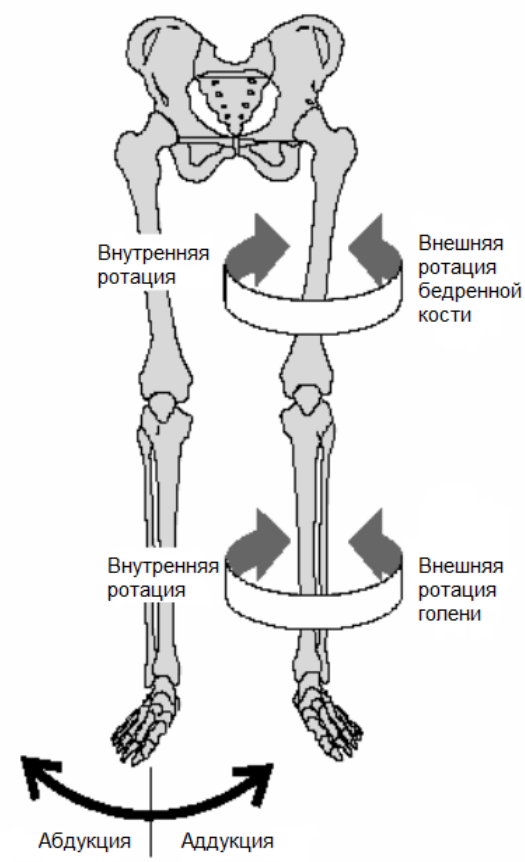

признаков с распределением, отличным от нормального - непараметрический U-критерий Уилкоксона (Манна-Уитни) с тем же уровнем значимости [5, 9]. В работе использовался универсальный математический пакет MathCad.

Для выявления связи между исследуемыми величинами проведен корреляционный анализ. При $г<0,30$ корреляция считалась слабой, при $\Gamma=0,31-0,70 \quad-$ средней, при $\Gamma=0,71-0,99$ сильной [9].

Определение тесноты взаимосвязей кинематических характеристик осуществлялось с помощью коэффициента ассоциации или тетрахорического показателя связи [9].

Для определения тесноты взаимосвязи кинематических характеристик была использована четырехпольная корреляционная таблица (табл. 1).

В таблице буквами А и В обозначены группы признаков, a - средние значения угла сгибания, $\mathrm{b}$-средние значения угла ротации большеберцовой кости, c - средние значения угла латерального смещения голени.

Значимость выборочного коэффициента корреляции оценивалась по величине критерия Пирсона $\chi^{2}$,

$$
\chi^{2}=\mathrm{n} \times r_{\mathrm{A}}^{2} \geq \chi_{\mathrm{st}}^{2}
$$

для принятого уровня значимости $(\alpha)$ и числа степеней свободы $\mathrm{R}=(2-1) \times(2-1)=1$.

Трактовка полученных результатов проводилась на основании градации степени (силы) корреляции [9].

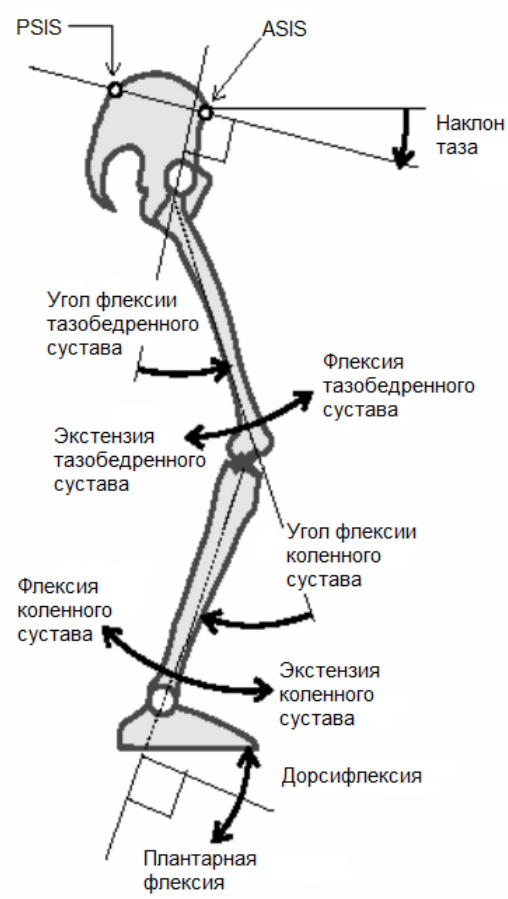

Рис. 2. Схема определения углов движения в коленном суставе Plug in Gait Full body [14]. 
Четырехпольная корреляционная таблица

\begin{tabular}{c|c:c:c} 
Альтернатив группы & Альтернатив характеристик & \\
\hline $\mathrm{A}$ & $\mathrm{a}$ & $\mathrm{b}$ & $\mathrm{a}+\mathrm{b}$ \\
\hline $\mathrm{B}$ & $\mathrm{c}$ & $\mathrm{a}$ & $\mathrm{c}+\mathrm{a}$ \\
\hline & $\mathrm{a}+\mathrm{c}$ & $\mathrm{a}+\mathrm{b}$ &
\end{tabular}
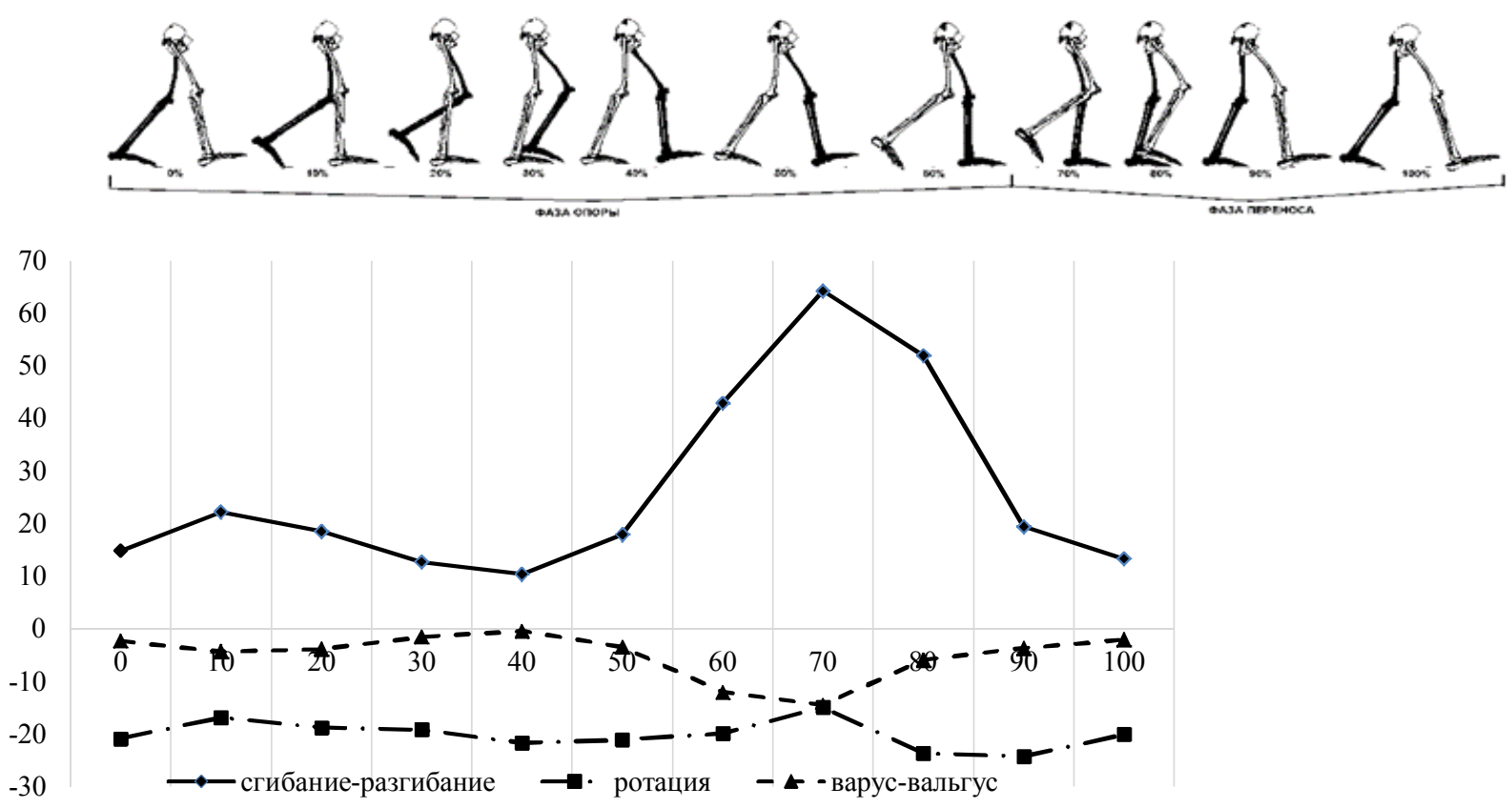

Рис. 3. Кинематические профили коленного сустава. Рабочая конечность - правая (на схеме обозначена более светлым цветом).

\section{РЕЗУЛЬТАТЫ ИССЛЕДОВАНИЯ И ИХ ОБСУЖДЕНИЕ}

Исследование показало, что в шаговом цикле на фазу опоры приходится $60 \%$ времени, на фазу переноса $-40 \%$ (рис. 3 ).

Сгибание в коленном суставе представляет собой движение с наибольшей амплитудой $53,8 \pm 1,2^{\circ}$. Как видно из рисунка 3 , средние величины угла сгибания в шаговом цикле меняются волнообразно, формируя два «пика»: меньший в начале фазы опоры $(10 \%$ от начала ШЦ) $22,2 \pm 0,7^{\circ}$ и больший - в фазе переноса $64,2 \pm 1,1^{\circ}$ (70\% от начала ШЦ).

В период от $20 \%$ до $40 \%$ от начала шагового цикла угол сгибания уменьшается, что обусловлено разгибанием в коленном суставе конечности, выполняющей роль опоры (рис. 3). Максимальное разгибание опорной конечности $\left(10,4 \pm 0,3^{\circ}\right)$ зафиксировано на отметке $40 \%$ от начала шагового цикла. Как видно из графика на рисунке 3, в завершении фазы опоры начинается сгибание конечности в коленном суставе. Угол сгибания достигает максимума в фазе переноса $64,2 \pm 1,1^{\circ}$ на отметке $70 \%$ от начала шагового цикла. Интенсивное разгибание в коленном суставе происходит при «выбрасывании» голени вперед. Этот процесс наиболее выражен в интервале между $80 \%$ и $90 \%$ времени шагового цикла, в завершении которого (на отметке 100\%) угол сгибания уменьшается на $50,9 \pm 1,1^{\circ}$ от точки максимального сгибания, составляя $13,3 \pm 0,5^{\circ}$.

Коленный сустав, по сути, обладает одной степенью свободы, позволяющей ему совершать движения вокруг горизонтальной оси [13]. Однако при сгибании в нем появляется дополнительная степень свободы - ротация голени вокруг вертикальной оси. При этом в качестве оси вращения выступает межмыщелковое возвышение большеберцовой кости [7]. Амплитуда осевой ротации голени в шаговом цикле невелика и составляет $9,4 \pm 0,4^{\circ}$. В фазе опоры (0-60\% времени ШЦ) этот показатель меняется незначительно, колеблясь между $-16,9 \pm 0,9^{\circ}$ и $-21,7 \pm 0,9^{\circ}$. В начале фазы переноса (70\% от начала ШЦ) средние значения угла 
ротации большеберцовой кости достигают значения $14,9 \pm 0,6^{\circ}$, что свидетельствует о максимальной внутренней ротации голени в момент наибольшего сгибания конечности в коленном суставе (рис. 3). При разгибании в коленном суставе (80-100\% от начала ШЦ) изменения средних значений углов характеризуют наружную ротацию большеберцовой кости в фазе переноса. Полученные данные можно соотнести с феноменом автоматической ротации в коленном суставе [7].

Анализ полученных данных позволил определить установку коленного сустава в каждой фазе шагового цикла. Отрицательные значения углов между продольными осями голени и бедра свидетельствуют о «вальгусном» положении колена на всем протяжении шагового цикла (рис. 3). Амплитуда этого движения составляет $12,9 \pm 0,5^{\circ}$.

В фазе опоры до точки $40 \%$ от начала ШЦ регистрируется увеличение угла между продольными осями голени и бедра до $-0,46 \pm 0,06^{\circ}$, что свидетельствует о смещении колена кнаружи (рис. 3). В завершении фазы опоры (50-60\% времени ШЦ) начинается движение коленного сустава в противоположную сторону, достигающее максимальных значений (по модулю) в фазе переноса (точка $70 \%$ от начала ШЦ) $-14,5 \pm 0,1^{\circ}$. Остальной период фазы переноса характеризуется «возвращением» колена в исходное положение.

В результате корреляционного анализа выявлена тесная связь между сгибанием в коленном суставе и установкой колена $(r=0,9)$, характеризующая латеральное смещение колена при разгибании нижней конечности в фазе опоры и медиальное его положение при сгибании в коленном суставе. Кроме того, одновременно с изменение установки колена происходит осевая ротация голени, о чем свидетельствует коэффициент корреляции $r=0,4$ (умеренная связь).

Связь кинематических показателей при максимальном сгибании в коленном суставе (точка 70\% от начала шагового цикла) характеризует коэффициент ассоциации средней силы $\left(\mathrm{r}_{\mathrm{A}}=0,6\right)$. При меньших значениях угла сгибания в коленном суставе (10\% от начала ШЦ) коэффициент ассоциации имеет слабую силу $(0,4)$, а при разгибании (40\% от начала ШЦ) этот коэффициент становится минимальным $(0,3)$.

По нашему мнению, меньшие значения коэффициента ассоциации при разгибании в коленном суставе в фазе опоры являются показателем его стабильности в этой точке шагового цикла. Значение угла между продольными осями голени и бедра в точке 40\% от начала ШЦ стремиться к нулю $\left(0,46 \pm 0,06^{\circ}\right)$, т.е. колено занимает среднее положение между вальгусной и варусной его установками, обеспечивая опорную роль всей конечности. При этом значение осевой ротации голени $\left(-21,7 \pm 0,8^{\circ}\right)$ свидетельствует о том, что при разгибании в фазе опоры голень также принимает практически среднее положение, поскольку этот показатель колеблется между $-16,9 \pm 0,9^{\circ}$ и $-24,3 \pm 0,9^{\circ}$, а амплитуда этого движения, как было указано выше, составляет $9,4 \pm 0,4^{\circ}$. По мнению А.И. Капанджи [7] именно при разгибании ось коленного сустава совпадает с механической осью нижней конечности, что исключает возможность осевой ротации голени и ее латеральное смещение. Коэффициент ассоциации средней силы, выявленный при сгибании голени, может расцениваться как характеристика меньшей стабильности коленного сустава в этом периоде шагового цикла.

Таким образом, амплитуда движений в коленном суставе в шаговом цикле у мужчин 17-25 лет по данным системы захвата и анализа движения составляет: сгибание - 53,8 $\pm 1,2^{\circ}$, осевая ротация голени - $9,4 \pm 0,4^{\circ}$, боковое смещение колена - $12,9 \pm 0,5^{\circ}$. Кинематические показатели коленного сустава в шаговом цикле тесно взаимосвязаны, о чем свидетельствует сильная корреляционная связь между сгибанием в коленном суставе и изменением установки колена, а также связь средней силы между установкой колена и осевой ротацией голени. Коэффициент ассоциации слабой силы является показателем стабильности коленного сустава при разгибании голени, а средней силы - меньшей стабильности при ее сгибании.

\section{ЛИТЕРАТУРА}

1. Автандилов Г.Г. Медицинская морфометрия. - М. : Медицина, 1990. - 384 с.

2. Александер Р. Биомеханика. - М. : Мир, 1970. 339 c.

3. Борзиков В.В. Видеоанализ движений человека в клинической практике (обзор) // СТМ. - 2015 T. 7, № 4. - С. 201-210.

4. Бунак B.B. Антропометрия : практический курс. M., 1941. -368 c.

5. Гублер Е.В. Информатика в патологии, клинической медицине и педиатрии. - Л., 1990. - 176 с.

6. Калмин О.В., Афанасиевская Ю.С., Самотуга А.В. Оценка особенностей антропометрических параметров и распределения соматотипов лиц юношеского возраста г. Краснодара и Краснодарского края // Известия высших учебных заведений. Поволжский регион. Медицинские науки. 2010. - № 1 (13). - C. 3-11.

7. Капанджи А.И. Нижняя конечность. Функциональная анатомия. - 6-е изд. - М. : Эксмо, 2009. 313 c.

8. Клиорин А.И., Чтецов В.П. Основные подходы и краткий исторический очерк развития учения о конституциях. Биологические проблемы учения о конституциях человека. - Л., 1979. - 320 с. 
9. Лакин Г.Ф. Биометрия : учеб. пособие. - М. : Высш. шк., 1990. - 352 с.

10. Лихачев С.А., Лукашевич В.А. Видеоанализ шагового движения: феноменология визуальной оценки // Международный неврологический журнал. - 2012. - Т. 2. - С. 178-182.

11. Морфология человека / Под ред. Б.А. Никитюка, В.П. Чтецова. - М. : Изд-во МГУ, 1990. - 344 с.

12. Муха Ю.П., Воробьев А.А., Безбородов С.А., Колмаков А.А. Метод расчета поверхности коленного сустава // Бюллетень Волгоградского научного центра РАМН. - 2009. - № 1. - С. 54-57.

13. Полещук Н.К. Основы гониометрической практики: Учеб. пособие для вузов и факультетов физической культуры / Петрозаводск : ГОУВПО «КГПУ», 2004. - 192 с.

14. Руководство по использованию программного модуля «Plug-In-Gait» [Электронный pecypc] // Plug-In-Gait. http:/wweb.uta.edu/faculty/ricard/Classes/KINE-

5350/PIGManualver1.pdf, свободный (23.08.2016)
15. Черноруцкий M.B. Учение о конституции в клинике внутренних болезней / Труды 7 съезда российских терапевтов. - Л., 1927. - С. 304-312.

16. Andriacchi T.P., Alexander E.J. Studies of human locomotion: past, present and future. // J Biomech. 2000. - Vol. 33, N 10. - P. 1217-1224. - doi: 10.1016/S0021-929(00)00061-0.

17. Herda L., Fua P., Plänkers R., Boulic R., Thalmann D. Using skeleton-based tracking to increase the reliability of optical motion capture. // Hum Mov Sci. - 2001. - Vol. 20, N 3. - P. 313-341. - doi: 10.1016/s0167-9457(01)00050-1.

18. Royo Sánchez A.C., Aguilar Martin J.J., Santolaria Mazo J. Development of a new calibration procedure and its experimental validation applied to a human motion capture system. // J Biomech Eng. - 2014. Vol. 136, N 12. - P. 124502. - doi: $10.1115 / 1.4028523$. 